\title{
Dietary sodium intake and the risk of airway hyperreactivity in a random adult population
}

John Britton, Ian Pavord, Kathie Richards, Alan Knox, Antoni Wisniewski, Scott Weiss, Anne Tattersfield

\begin{abstract}
Background - High dietary sodium intake has been identified as a potential cause of asthma and airway hyperreactivity. This study was designed to test the hypothesis that dietary sodium intake is an independent determinant of the risk of hyperreactivity in the general population, and to assess the role of atopy in the association between these factors.

Methods - Airway reactivity to methacholine, atopy, 24 hour urinary sodium excretion, and self-reported smoking and symptom history were measured in a random sample of 1702 adults aged 18-70 from an administrative district of Nottingham. Hyperreactivity was defined as a $\mathrm{PD}_{20} \mathrm{FEV}_{1}$ of $12.25 \mu \mathrm{mol}$ or less, and atopy was defined quantitatively as the mean allergen skin weal response to Dermatophagoides pteronyssinus, cat fur, and grass pollen, and categorically as the occurrence of any allergen response $1 \mathrm{~mm}$ or greater than the saline control. Multiple logistic regression analysis was used to estimate the independent relative odds of hyperreactivity, atopy, or symptoms in relation to sodium excretion in all 1702 subjects, and multiple linear regression to assess the independent relation between sodium excretion and mean allergen skin weal diameter, and the $\mathbf{P D}_{20}$ value amongst hyperreactive subjects.
\end{abstract}

Results - There was no relation between the relative odds of hyperreactivity to methacholine and 24 hour urinary sodium excretion, either before or after adjustment for age, smoking, allergen skin weal diameter, and sex, and similarly no relation if the analysis was restricted to men or women only. The relative odds of having at least one allergen skin test response $1 \mathrm{~mm}$ greater than the saline control were increased in relation to sodium excretion after adjustment for age, sex, and smoking by a ratio of $2.08(95 \%$ CI 1.04 to $4 \cdot 15)$ per $\log _{10}$ unit increase in sodium excretion, but there was no evidence of an association between sodium excretion and the occurrence of self-reported wheeze, hay fever, eczema, or asthma. There was no relation between 24 hour sodium excretion and the magnitude of the mean allergen skin weal response or the $\mathbf{P D}_{20}$ value. Conclusions - These findings do not support the hypothesis that a high dietary sodium intake is a risk factor for airway hyperreactivity or atopic disease in the general adult population.

(Thorax 1994;49:875-880)

Asthma is common in most urbanised or economically developed populations, but is reported to be rare in rural subsistence societies. ${ }^{1-6}$ This suggests that environmental factors associated with an affluent lifestyle may be involved in the aetiology of asthma, but the exposures responsible have not been identified. Burney suggested that one factor which may be important is the high intake of dietary sodium characteristic of economically developed countries ${ }^{78}$ and, in support of this hypothesis, reported ecological evidence linking regional differences in mortality from asthma in England and Wales with differences in table salt intake. ${ }^{9}$ In a study carried out in collaboration with us he also reported a cross sectional association between airway hyperreactivity and 24 hour sodium excretion in adult men, ${ }^{10}$ and experimental data have subsequently been reported to show that changes in dietary sodium intake can influence levels of airway reactivity or peak flow levels in patients with asthma. ${ }^{11-14}$ Other epidemiological studies have also suggested associations between a high dietary sodium intake and a higher prevalence of self-reported wheeze in adults $^{15}$ and children. ${ }^{16}$

Not all of the evidence is consistent with this hypothesis, however, since three epidemiological surveys ${ }^{17-19}$ and at least one experimental study ${ }^{20}$ have found no evidence of an association between asthma and sodium intake. Also, much of the evidence linking sodium and asthma is derived from studies in men, and there is relatively little information on whether the same relationship also applies in women. The primary objective of the present study was therefore to test the hypothesis that sodium intake and airway hyperreactivity are associated in the general population by investigating a large random sample of both men and women. The secondary objective was to establish whether any relation between these variables was mediated by an effect of sodium on the prevalence or severity of atopy.

\section{Methods}

SUBJECTS

Subjects were identified by systematic sampling from a random starting point in the electoral register of a local authority area in Nottingham. 
From a total population of approximately 87000 adults we identified 7106 names and wrote to each asking them to participate in the study. In the letter we asked all subjects who were aged between 18 and 70 years on 1 January 1991 to attend their local general practice surgery or health centre for a questionnaire assessment and lung function tests, having abstained from inhaled bronchodilators for four hours and from oral bronchodilators for eight hours prior to their appointment.

\section{STUDY DESIGN}

On attending for the study subjects were interviewed by a doctor who explained the protocol, ascertained any medical contraindication to methacholine challenge, and obtained written consent. Subjects then completed a computer delivered food frequency questionnaire (DietQ Tinuviel Software, Stoke Gifford, Bristol, UK) followed by a questionnaire on smoking and respiratory symptoms adapted from the IUATLD questionnaire. ${ }^{21}$ Forced expiratory volume in one second $\left(\mathrm{FEV}_{1}\right)$ and forced vital capacity (FVC) were then measured with the subject seated after 20 minutes rest using a dry bellows spirometer (Vitalograph, Buckingham, UK), taking the best of three technically satisfactory manoeuvres. Allergen skin sensitivity to Dermatophagoides pteronyssinus, cat fur, and grass pollen solutions (Bencard, UK) was then measured by skin prick testing, with saline and histamine controls, the response to each allergen being measured as the mean of two right angled skin weal diameters of which one was the largest measurable diameter excluding pseudopods and flares. Airway reactivity to methacholine was measured by the method of Yan et al ${ }^{22}$ in which methacholine was administered until the $\mathrm{FEV}_{1}$ had fallen by $20 \%$ or more from the post-saline value, or until a maximum cumulative dose of $12 \cdot 25 \mu \mathrm{mol}$ had been given. Doubling increments of dose from $0.048 \mu \mathrm{mol}$ were administered to subjects with a past history of asthma or wheezing, and quadrupling increments from $0.096 \mu \mathrm{mol}$, changing to doubling increments if $\mathrm{FEV}_{1}$ fell by $10 \%$ or more, in persons with no history of asthma or wheeze. $\mathrm{PD}_{20}$ values were calculated by linear interpolation on a log dose-response plot. Methacholine was not given to subjects with a baseline $\mathrm{FEV}_{1}$ less than $60 \%$ of their predicted value ${ }^{23}$ or less than 1.5 litres. The procedure for 24 hour urine collection was then explained, and subjects were provided with a 5 litre collection bottle and asked to record details of the time the urine sample collection started and finished. Women were also asked to provide the date of their last menstrual period. Returned samples were weighed to estimate volume, and an aliquot was separated and sent for estimation of sodium and potassium concentrations by flame photometry and of creatinine by the modified Jaffe reaction.

Subjects who did not respond to our letter or who did not attend for assessment were sent a written reminder, and if possible were telephoned to establish the reason for not taking part. The names of those we were unable to contact were subsequently checked against local health authority records and updated electoral registers and telephone listings when these became available, to try to identify those who had moved away from the area. The study was part of a wider survey of the association between diet and chronic lung disease approved by the Nottingham City Hospital and University ethics committees, and was completed between January and May 1991.

\section{DATA ANALYSIS}

Atopy was defined qualitatively as the occurrence of at least one skin allergen skin weal diameter greater than $1 \mathrm{~mm}$ more than the saline control, and quantitatively as the mean response in millimetres to the three allergen extracts after subtraction of the saline response. Hyperreactivity to methacholine was defined as a $\mathrm{PD}_{20}$ of $12.25 \mu \mathrm{mol}$ or less. Ever-smokers were defined as those who had smoked as much as one cigarette per day for one year, and categorised as current or ex-smokers according to whether they had smoked within one month of the study. Twenty four hour urinary sodium, potassium, and creatinine excretions were estimated by multiplication of the respective aliquot concentrations by urinary volume, with linear adjustment for duration of the sampling if this was reported to be other than 24 hours, and $\log$ transformed to achieve a normal distribution for all analyses. Descriptive statistics, cross tabulations, and univariate comparisons were carried out using SPSS-PC version 4.0. ${ }^{24}$ The relative odds of hyperreactivity, atopy, or self-reported past history of wheeze, diagnosed asthma, eczema, or hay fever were estimated in relation to 24 hour urinary sodium excretion with adjustment for confounding effects by multiple logistic regression using the program EGRET. ${ }^{25}$ Similar analyses in which mean allergen skin weal diameter in the total population, and $\log _{10} \mathrm{PD}_{20}$ in subjects in whom $\mathrm{PD}_{20}$ was measurable at $12.25 \mu \mathrm{mol}$ or less were regressed as continuous variables, were carried out using multiple linear regression in SPSSPC.

\section{Results}

Of the original sample of 7106 we succeeded in contacting 4485 , and established that a further 1586 subjects were outside the specified age range, or had died or left the area. We were unable to contact and have no information about 1035 individuals who did not reply to our initial letter or subsequent two reminders and could not be contacted by telephone, but remained listed as living at the given address at the time of the study. A total of 2644 (representing between $48 \%$ and $59 \%$ of those potentially eligible) attended and completed the dietary and respiratory questionnaire. Methacholine challenge was contraindicated by a resting $\mathrm{FEV}_{1}$ of less than $60 \%$ predicted or less than 1.5 litres in 102 of these, by pregnancy or breastfeeding in 40 , and by significant nonrespiratory illness in 36. Methacholine was refused by 51 subjects. Airway reactivity was therefore measured in 2415 , and details of this group have been presented elsewhere. ${ }^{26}$ Since 
no further information was obtained on those who did not attend for the study we cannot comment on the nature of any bias in participation.

A 24 hour urine sample was returned by 1702 of those in whom methacholine reactivity was measured, and the present analysis is restricted to these individuals. Details of the distributions of age, sex, smoking history, atopic and reactivity status are shown in table 1 . Of these subjects, 96 had been prescribed an inhaled $\beta$ agonist and 54 were using regular inhaled steroids. No subject had been prescribed salmeterol. Comparison of the 1702 subjects who returned urine samples with the 2415 in whom reactivity was measured ${ }^{26}$ reveals that urine samples were returned by a slightly lower proportion of younger subjects $(31 \%$ of the 1702 were aged under 40 compared with $38 \%$ of the 2415), but no bias in terms of sex, atopy, or smoking. Mean (SD) baseline $\mathrm{FEV}_{1}$ in these subjects was $3.20(0.85)$ litres, equivalent to 102 (15) $\%$ of predicted..$^{23}$ Hyperreactivity to methacholine was observed in $222(11.8 \%)$ subjects. The time at which the 24 hour urine collection began and ended was recorded specifically by 1538 subjects $(90 \%)$ and the duration of the collection was between 23 and 25 hours in $93 \%$ of these.

Geometric mean (95\% range) estimated 24 hour urinary sodium excretion was 168 (78362) mmol, potassium $85(45-160) \mathrm{mmol}$, and creatinine $13.2(6 \cdot 9-25 \cdot 3) \mathrm{mmol}$. Direct examination of the extremes of the range of 24 hour sodium revealed none that was also extreme for

Table 1 Number, sex, age group, and atopic, smoking and reactor status of study population

\begin{tabular}{|c|c|c|c|c|c|c|}
\hline & \multicolumn{5}{|c|}{ Age group } & \multirow[t]{2}{*}{ Total } \\
\hline & $18-29$ & $30-39$ & $40-49$ & $50-59$ & $60-70$ & \\
\hline Number & 185 & 336 & 467 & 400 & 314 & 1702 \\
\hline $\begin{array}{c}\text { Women } \\
\text { n } \\
\%\end{array}$ & $\begin{array}{l}96 \\
52\end{array}$ & $\begin{array}{r}174 \\
52\end{array}$ & $\begin{array}{r}231 \\
50\end{array}$ & $\begin{array}{r}207 \\
52\end{array}$ & $\begin{array}{r}145 \\
46\end{array}$ & $\begin{array}{r}853 \\
50\end{array}$ \\
\hline $\begin{array}{c}\text { Atopics } \\
\text { n } \\
\%\end{array}$ & $\begin{array}{r}104 \\
56\end{array}$ & $\begin{array}{r}173 \\
51\end{array}$ & $\begin{array}{r}187 \\
40\end{array}$ & $\begin{array}{r}159 \\
40\end{array}$ & $\begin{array}{r}101 \\
32\end{array}$ & $\begin{array}{r}724 \\
43\end{array}$ \\
\hline $\begin{array}{l}\text { Never smokers } \\
\text { n } \\
\%\end{array}$ & $\begin{array}{r}141 \\
76\end{array}$ & $\begin{array}{r}201 \\
60\end{array}$ & $\begin{array}{r}218 \\
47\end{array}$ & $\begin{array}{r}195 \\
49\end{array}$ & $\begin{array}{r}118 \\
38\end{array}$ & $\begin{array}{r}873 \\
51\end{array}$ \\
\hline $\begin{array}{l}\text { Current smokers } \\
\text { n } \\
\%\end{array}$ & $\begin{array}{l}28 \\
15\end{array}$ & $\begin{array}{l}60 \\
18\end{array}$ & $\begin{array}{r}111 \\
24\end{array}$ & $\begin{array}{l}79 \\
20\end{array}$ & $\begin{array}{l}59 \\
19\end{array}$ & $\begin{array}{r}337 \\
20\end{array}$ \\
\hline $\begin{array}{l}\mathrm{PD}_{20}<12.25 \mu \mathrm{mol} \\
\mathrm{n} \\
\%\end{array}$ & $\begin{array}{l}21 \\
11\end{array}$ & $\begin{array}{l}49 \\
15\end{array}$ & $\begin{array}{l}48 \\
10\end{array}$ & $\begin{array}{l}56 \\
14\end{array}$ & $\begin{array}{l}48 \\
15\end{array}$ & $\begin{array}{r}222 \\
13\end{array}$ \\
\hline
\end{tabular}

potassium and creatinine, so no 24 hour sodium estimates were excluded as obvious outliers. Geometric mean 24 hour sodium excretion was significantly related to age, decreasing by a mean (SE) of $0.22(0.07) \%$ per year $(p=0.02)$ and was significantly higher in men and in current smokers (table 2). There was no significant difference in geometric mean sodium excretion between reactors and non-reactors, the mean value being $5 \mathrm{mmol} / 24$ hours higher ( $95 \%$ geometric confidence interval (CI) -10 to +14$)$ in the group who did not react to methacholine. Sodium excretion was, however, significantly higher amongst subjects with at least one positive skin test by $10 \mathrm{mmol} / 24$ hours ( $95 \%$ CI 4.5 to $17 \cdot 1, \mathrm{p}<0.001$ ).

Multiple logistic regression of reactor status against urinary 24 hour sodium excretion confirmed that there was no significant relation between these variables, either before or after correction for potential confounding by sex, age, smoking status or atopy, or adjustment for urinary excretion of creatinine (table 3 ). There was also no relation between 24 hour sodium excretion and the log transformed $\mathrm{PD}_{20} \mathrm{FEV}_{1}$ value in subjects in whom $\mathrm{PD}_{20}$ was measurable at $\leqslant 12.25 \mathrm{mmol}$, either in univariate or multivariate analysis. There was no relation between hyperreactivity and 24 hour potassium excretion. These findings did not differ appreciably if the analysis was restricted only to men or to women, if adjustment was made for the timing of the urinary collection relative to the menstrual cycle in women, if smoking was measured in pack-years rather than a categorical variable, or if baseline $\mathrm{FEV}_{1}$ or $\mathrm{FEV}_{1} \%$ predicted, or current asthma drug use were included in the analysis.

Logistic regression of atopic status revealed that the odds of having at least one positive skin test were increased in relation to 24 hour sodium excretion by an independent odds ratio of $2.08(95 \%$ CI 1.04 to 4.15$)$ per unit $\log _{10}$ difference in urinary sodium excretion (table 4). However, this finding was of borderline statistical significance $(p<0.05)$ and there was no significant association, either with or without adjustment for age, sex and smoking, between sodium excretion and the magnitude of the allergen skin weal diameter. There was no evidence that 24 hour potassium excretion was related to atopy.

Wheezing ever was reported by $21 \%$ of the

Table 2 Mean (SD) $\log _{10} 24$ hour sodium excretions, geometric mean values, and mean (SE) differences in $\log _{10}$ mmol between categories for sex, smoking, atopy, and reactor status

\begin{tabular}{lrllll}
\hline & $n$ & $\begin{array}{l}\text { Mean }(S D) \log _{10} \\
\text { sodium excretion }\end{array}$ & $\begin{array}{l}\text { Geometric mean } \\
(\text { mmol })\end{array}$ & $\begin{array}{l}\text { Mean }(S E) \text { difference } \\
\left(\log _{10} \text { mmol }\right)\end{array}$ & $p$ \\
\hline Men & 849 & $2.294(0.155)$ & 197 & $0.136(0.008)$ & $<0.001$ \\
Women & 853 & $2.158(0.156)$ & 144 & & \\
Never smokers & 873 & $2.216(0.167)$ & 164 & $0.016(0.009)$ & $0.102^{*}$ \\
Ex-smokers & 492 & $2.232(0.171)$ & 170 & $0.026(0.011)$ & $0.017^{*}$ \\
Current smokers & 337 & $2.242(0.175)$ & 175 & $0.011(0.012)$ & 0.354 \\
Reactors & 222 & $2.216(0.177)$ & 164 & & \\
Non-reactors & 1480 & $2.227(0.169)$ & 169 & $0.029(0.008)$ & $<0.001$ \\
Atopic & 724 & $2.239(0.166)$ & 173 & & \\
Non-atopic & 978 & $2.211(0.172)$ & 163 & &
\end{tabular}

${ }^{*} \mathrm{p}$ value applies to comparison with never smokers. 
Table 3 Independent odds ratios, $p$ values, and confidence intervals for the effects of sex, age, smoking status, atopy, and $\log _{10} 24$ hour urinary sodium and creatinine excretion on the odds of reacting to methacholine

\begin{tabular}{|c|c|c|c|}
\hline & Odds ratio & $p$ & $\begin{array}{l}95 \% \text { confidence } \\
\text { interval }\end{array}$ \\
\hline $\begin{array}{l}\text { Intercept (man, non-smoker, skin test } \\
\text { negative, age } 18, \log _{10} \text { sodium and } \\
\text { creatinine excretion }=0 \text { ) }\end{array}$ & 0.024 & & 0.002 to 0.275 \\
\hline Women & 1.830 & 0.002 & $1 \cdot 240$ to $2 \cdot 702$ \\
\hline Atopy (per mm skin weal) & $1 \cdot 414$ & $<0.001$ & 1.324 to 1.510 \\
\hline Age (per year from 18) & 1.026 & $<0.001$ & 1.013 to 1.040 \\
\hline $\begin{array}{l}\text { Smoking: } \\
\text { Ex-smokers } \\
\text { Current smokers }\end{array}$ & $\begin{array}{l}0.948 \\
1.779\end{array}$ & $0.006^{*}$ & $\begin{array}{l}0.655 \text { to } 1.372 \\
1.215 \text { to } 2.604\end{array}$ \\
\hline $\begin{array}{l}24 \text { hour sodium }\left(\log _{10} \mathrm{mmol}\right) \\
24 \text { hour creatinine }\left(\log _{10} \mathrm{mmol}\right)\end{array}$ & $\begin{array}{l}1 \cdot 183 \\
0 \cdot 794\end{array}$ & $\begin{array}{l}0.752 \\
0 \cdot 749\end{array}$ & $\begin{array}{l}0.417 \text { to } 3.357 \\
0.193 \text { to } 3.265\end{array}$ \\
\hline
\end{tabular}

Table 4 Independent odds ratios, $p$ values, and confidence intervals for the effects of sex, age, smoking status and $\log _{10} 24$ hour urinary sodium and creatinine excretion on the odds of any one positive skin test

\begin{tabular}{llll}
\hline & Odds ratio & $p$ & $\begin{array}{l}95 \% \text { confidence } \\
\text { interval }\end{array}$ \\
\hline $\begin{array}{l}\text { Intercept (man, non-smoker, age 18, } \log _{10} \\
\text { sodium and creatinine excretion =0) }\end{array}$ & 0.401 & & 0.080 to 2.012 \\
Women & 0.780 & 0.055 & 0.605 to 1.006 \\
Age (per year from 18) & 0.975 & $<0.001$ & 0.967 to 0.983 \\
$\begin{array}{l}\text { Smoking: } \\
\quad \text { Ex-smokers }\end{array}$ & 1.043 & $0.054^{*}$ & 0.824 to 1.320 \\
$\quad$ Current smokers & 0.749 & & 0.574 to 0.979 \\
24 hour sodium $\left(\log _{10} \mathrm{mmol}\right)$ & 2.078 & 0.038 & 1.040 to 4.152 \\
24 hour creatinine $\left(\log _{10} \mathrm{mmol}\right)$ & 0.884 & 0.800 & 0.339 to 2.304 \\
\hline
\end{tabular}

${ }^{*} \mathrm{p}$ value applies to exclusion of all categories of smoking from model.

Table 5 Independent odds ratios, $p$ values, and confidence intervals for the effects per unit increase in $\log _{10} 24$ hour sodium excretion, adjusted for age, sex, smoking status, creatinine excretion, and mean skin weal diameter, on the occurrence of a self-reported past history of wheeze, diagnosed asthma, eczema or hay fever

\begin{tabular}{llll}
\hline & Odds ratio & $p$ & $\begin{array}{l}95 \% \text { confidence } \\
\text { limits }\end{array}$ \\
\hline Wheeze ever & 1.50 & 0.350 & 0.64 to 3.51 \\
Diagnosed asthma & 2.69 & 0.136 & 0.73 to 9.86 \\
Eczema & 0.66 & 0.273 & 0.31 to 1.39 \\
Hay fever & 0.43 & 0.049 & 0.18 to 0.99 \\
\hline
\end{tabular}

population sample, and ever diagnosed asthma by $7.9 \%$, hay fever by $25 \%$, and eczema by $27.6 \%$. There was no evidence that the occurrence of these symptoms was increased in relation to 24 hour urinary sodium excretion, with or without adjustment for age, sex, smoking, or creatinine excretion, the only significant finding being that the occurrence of selfreported hay fever was reduced in relation to a higher sodium excretion $(\mathrm{p}<0.05$, table 5$)$.

\section{Discussion}

In view of the extent of the public health problem presented by asthma in economically developed countries, and the potential reversibility of a high sodium diet, the hypothesis that sodium may be involved in the aetiology of asthma ${ }^{9}$ merits careful investigation. When the present study was designed all of the findings relevant to this hypothesis reported in the literature were consistent with an association between proxy measures of sodium intake and either self-reported asthma symptoms or objective measures of airway hyperreactivity, ${ }^{9-12} 15$ but at that time our own study was the only investigation of the relation between hyperreactivity and sodium intake in the general population. ${ }^{10}$ In that study we found an association which was strong, being equivalent to an approximately 24 fold increase in the relative odds of hyperreactivity per $\log _{10}$ unit increase in 24 hour sodium excretion, but was of borderline statistical significance in our sample of 138 adult men. The primary objective of the present study was to measure the magnitude of the relation between sodium excretion and the occurrence of airway hyperreactivity with greater precision by using a substantially larger sample of both men and women. The study was sufficiently large to detect a relative risk of similar magnitude to our previous estimate ${ }^{10}$ with $95 \%$ power.

Our secondary objective, of assessing the role of atopy in mediating an association between sodium intake and airway hyperreactivity, arose from the observation that the differences in asthma prevalence between urbanised and rural subsistence societies which gave rise to the sodium hypothesis also appear to occur with other markers or manifestations of atopy, including eczema, hay fever, or allergen specific IgE levels. ${ }^{2527}$ It follows that, if higher sodium intake is involved in the higher prevalence of asthma in these countries, then sodium intake should also be related to the prevalence of other atopic diseases and, more specifically, to markers of either the prevalence or severity of atopy. We therefore investigated the relation between sodium excretion and the prevalence and degree of allergen skin sensitivity, and assessed the relation between sodium excretion and the prevalence of self-reported wheeze, diagnosed asthma, hay fever, and eczema.

The findings of the present study are based on a large number of adults drawn at random from a geographically defined population. The distributions of estimates of 24 hour sodium, potassium and creatinine excretion in our study sample were very similar to previous externally validated estimates reported in the United Kingdom, ${ }^{28}$ and the prevalence of positive skin tests and of airway hyperreactivity were also similar to previous reports using similar methodology in general population samples. ${ }^{29-31}$ Resting $\mathrm{FEV}_{1}$ in the sample was also close to predicted values. Thus, whilst the proportion of current smokers in our sample was approximately $10 \%$ lower than in our previous study, ${ }^{10}$ and approximately $10 \%$ lower than that expected from an independent estimate of local smoking prevalence, ${ }^{32}$ the population sample studied is in other respects similar to that previously reported ${ }^{10}$ and is probably broadly representative of the general population. We used methacholine instead of histamine as the non-specific inhalation challenge agent in this 
study because the favourable side effect profile of methacholine allowed us to measure $\mathrm{PD}_{20}$ values up to an equipotent bronchoconstrictor dose to that used previously without the need for extrapolation of the dose-response curve, but in all other respects the exclusion criteria applied, the methods of measurement and the analysis presented are similar to those used previously. ${ }^{10}$ Contrary to expectation we found no evidence of an association between sodium excretion and airway hyperreactivity in the total population or in either men or women. This was true whether hyperreactivity was analysed as a categorical variable or as a continuous variable within the group who were hyperreactive and in whom $\mathrm{PD}_{20}$ was therefore quantified. After adjustment for age, sex, smoking, and atopy we found that the estimated effect on hyperreactivity was weak, with an odds ratio of only 1.18 per tenfold increase in sodium excretion, which was substantially smaller than our previous finding and not statistically significant. Since these results are derived from a random population sample more than 10 times larger than our previous study, ${ }^{10}$ and larger than any other reported in the literature to date, we argue that our data provide strong evidence against the existence of a major aetiological association between sodium excretion and airway hyperreactivity.

Since 1990, when our study was designed, we are aware of four further epidemiological studies that have addressed the association between sodium intake and hyperreactivity. ${ }^{16-19}$ Two of these used 24 hour sodium excretion as a measure of sodium intake in adult men ${ }^{1718}$ and, although one found an association with potassium excretion, ${ }^{17}$ neither found a relation between hyperreactivity and sodium excretion. The sample sizes in these studies were relatively small, however, being less than 300 , so the failure to detect an association in these studies could therefore have been a false negative error. A recent study using seven day dietary diaries to measure sodium and potassium intake in adults found no significant relation between sodium intake and either airway hyperreactivity or asthma symptoms, ${ }^{19}$ but again the sample was fewer than 300 individuals. In contrast, a larger study of children and adolescents of both sexes found that, amongst males, the prevalence of wheeze was increased in relation to selfreported table salt use and airway reactivity was increased in relation to morning urinary potassium concentration. ${ }^{16}$ These relationships were not observed in females, however, and there was no association between urinary sodium concentration and symptoms or hyperreactivity in either sex. The epidemiological evidence available to date therefore remains equivocal, though it is possible that this is partly due to a relative lack of statistical power and, in one study, possibly also to the use of relatively imprecise methods of measuring sodium intake. ${ }^{16}$ The findings of the present study, which has used 24 hour urinary sodium samples to estimate sodium intake in a substantially larger sample of subjects, provide more conclusive evidence that there is no strong relation between these variables.
The question therefore arises as to why the early reports all supported the hypothesis, and several factors may have contributed to this. One is that the reported associations between sodium intake and respiratory symptoms or hyperreactivity arose from confounding, possibly by cigarette smoking. Smokers have a high dietary sodium intake relative to non-smokers ${ }^{33}$ and smoking is associated with both airway hyperreactivity ${ }^{3034-39}$ and with the occurrence of self-reported wheeze in children and adults. ${ }^{40-43}$ Incomplete control of confounding by active or passive smoking may therefore have contributed to the reported epidemiological associations between sodium intake and hyperreactivity or symptoms of asthma. ${ }^{101516}$ Confounding by smoking is also a potential problem in the present study, but may have been less of an influence because the overall prevalence of current smoking in the present study population was relatively low. However, confounding by smoking would not explain the existing experimental evidence that manipulation of dietary sodium can influence airway reactivity or airflow. Although one experimental study was negative ${ }^{20}$ and one uncontrolled, ${ }^{11}$ three have reported small but significant effects ${ }^{12-14}$ following changes in dietary sodium which are unlikely to have been associated with changes in smoking behaviour. Unless these findings are due to experimental error, changes in dietary sodium intake must either directly affect airway reactivity or influence exposure to other unrecognised causally related dietary factors. One explanation for these findings is that a change in dietary sodium intake does have a short term effect on airway reactivity, possibly mediated through changes in levels of endogenous steroid or catecholamine release, but that this effect is either not sustained or is not of sufficient magnitude to be important in population terms. An alternative explanation is that the effect of sodium restriction or supplementation in the intervention studies is actually attributable to the effects of other dietary constituents, the intake of which is somehow correlated with or influenced by sodium intake. Previous studies have suggested that potassium may be involved in this way, ${ }^{1617}$ but this was not confirmed in the present study.

The other objective of this study was to determine whether sodium intake was related to the prevalence or severity of atopy, or to the reporting of symptoms of atopic disease. We found that the occurrence of any one positive skin test response was higher in relation to a high 24 hour sodium excretion, though the data demonstrate that, with an odds ratio for skin test positivity of approximately two per tenfold change in sodium excretion, and an independent probability of 0.038 , the relation is weak in both magnitude and significance. Furthermore, if a high sodium intake caused allergen skin sensitivity, a dose-related relation between the magnitude of the skin weal response and sodium excretion would be expected, but was not seen in this study. A relation between sodium excretion and the reporting of clinical manifestations of atopic disease would also be expected, but again was not seen in the present 
study; in fact, the risk of self-reported hay fever was if anything lower in relation to a high sodium intake. The finding of an association between sodium excretion and any positive skin test is therefore inconsistent with our other results, and is perhaps more likely to be a false positive finding. We have explored this possibility further by investigating the relation between 24 hour sodium excretion and the prevalence of positive skin tests in data from the normative ageing study reported previously ${ }^{17}$ and again found no evidence of a relation between these variables (Sparrow D, Weiss ST, unpublished observations). On the basis of these findings we therefore conclude that dietary sodium is unlikely to be an important determinant of the risk of hyperreactivity or atopic disease in the general adult population.

The authors thank Cynthia Stacey for assistance with biochemical analyses; Irfran Wahedna, Colin Wong and William Kinnear for assistance with the survey fieldwork; the National Asthma Campaign and British Lung Foundation for financial support, the general practitioners and their colleagues who allowed us to the general practitioners and their colleagues who allowed us to
use their premises to conduct the fieldwork, and the people of use their premises to conduct the field
Gedling who took part in the study.

1 Godfrey RC. Asthma and IgE levels in rural and urban communities of the Gambia. Clin Allergy 1975;5:201-7.

2 Merrett TG, Merrett J, Cookson JB. Allergy and parasites: the measurement of total and specific IgE levels in urban and rural communities in Rhodesia Clin Allergy 1976;6:131-4.

3 Van Niekerk CH, Weinberg EG, Shore SC, Heese HDe V. Prevalence of childhood asthma in Africa. Lance Prevalence

4 Van Niekerk $\mathrm{CH}$, Weinberg EG, Shore SC, Heese HDe V, Van Shalkwyk DJ. Prevalence of asthma: a comparative
study of urban and rural Xhosa children. Clin Allergy study of urban

5 Waite DA, Eyles EF, Tonkin SL, O'Donnell TV. Asthma prevalence in Tokelauan children in two environments. Clin Allergy 1980;10:71-5.

6 Keeley DJ, Neill P, Gallivan S. Comparison of the prevalence of reversible airways obstruction in rural and urban Zimbabwean children. Thorax 1991;46:549-53.

7 Froment A, Milton H, Gravier Ch. Relation entre concommation sodee et hypertension arterielle. Contribution de l'epidemiologie geographique. Rev Epidemiol Sante Publique 1979;27:437-54.

8 Gleibermann L. Blood pressure and dietary salt in human populations. Ecol Food Nutr 1973;2:143-56.

9 Burney PGJ. The causes of asthma - does salt potentiate bronchial activity? Discussion paper. $\mathcal{f} R$ Soc Med 1987;80:364-7.

10 Burney PGJ, Britton JR, Chinn S, Tattersfield AE, Platt HS, Papacosta AO, et al. Response to inhaled histamine and 24 hour sodium excretion $B M F$ 1986;292:1483-6.

11 Javaid A, Cushley MJ, Bone MF. Effect of dietary salt on bronchial reactivity to histamine. $B M \mathcal{A} 1988 ; 297: 454$.

12 Burney PGJ, Neild JE, Twort CHC, Chinn S, Jones TD, Mitchell WD, et al. Effect of changing dietary sodium on the airway response to histamine. Thorax 1989;44:36-41.

13 Carey OJ, Locke C, Cookson JB. Effect of alterations of dietary sodium on the severity of asthma in men. Thorax 1993;48:714-8.

14 Medici TC, Vetter W. Bronchialasthma und Kochsalz. Schweiz Med Wochenschr 1991;121:501-8.

15 Schwartz J, Weiss ST. Dietary factors and their relation to respiratory symptoms. Am J Epidemiol 1990;132:67-76.

16 Pistelli R, Forastiere F, Corbo GM, Dell'Orco V, Brancato G, Agibiti N, et al. Respiratory symptoms and bronchial responsiveness are related to dietary salt intake and urinary potassium excretion in male children. Eur Respir 7 1993;6:517-22.

17 Sparrow D, O'Connor GT, Rosner B, Weiss ST. Methacholine airway responsiveness and 24-hour urine excretion of sodium and potassium. Am Rev Respir Dis 1991;144:722-5.

18 Beach JR, Young CL, Dennis JH, Williams SE, Avery AJ,
Walters EH, et al. A survey of airway responsiveness to methacholine and urinary sodium excretion. Thorax 1992;47:856.

19 Cerveri I, Bruschi C, Zoia MC, Fanfulla F, Berrayah L, Alesina MR, et al. Chronic respiratory symptoms, bronchial responsiveness and dietary sodium and potassium: a population-based study. Am Rev Respir Dis 1993; 147:A376.

20 Lieberman D, Heimer D. Effect of dietary sodium on the severity of bronchial asthma. Thorax 1992;47:360-2.

21 Burney PGJ, Laitinen LA, Perdrizet S, Huckauf H, Tattersfield AE, Chinn, et al. Validity and repeatability of the IUATLD (1984) bronchial symptoms questionnaire: an international comparison. Eur Respir $\mathcal{f}$ 1989;2:940-5.

22 Yan K, Salome C, Woolcock AJ. A rapid method for measurement

23 Quanjer PH. Standardised lung function testing. Bull Eur Physiopathol Respir 1983;19(Suppl 5):5-92.

24 Norusis MJ/SPSS Inc. SPSS/PC + 4.0 Base Manual, Chicago: SPSS Inc, 1990.

25 Statistics and Epidemiology Research Corporation. EGRET. Seattle: SERC, 1988

26 Britton J, Pavord I, Richards K, Knox A, Wisniewski A, Wahedna I, et al. Factors influencing the occurrence of airway hyperreactivity in the general population: the importance of atopy and airway calibre. Eur Respir $\mathcal{f} 1994$ 7:881-7.

27 Pattemore PK, Asher MI, Harrison AC, Mitchell EA, Rea $\mathrm{HH}$, Stewart AW. Ethnic differences in prevalence of asthma symptoms and bronchial hyperresponsiveness in New Zealand schoolchildren. Thorax 1989;44:168-76.

28 Williams DRR, Bingham SA. Sodium and potassium intakes in a representative population sample: estimation from $24 \mathrm{~h}$ urine collections known to be complete in a Cambridgeshire village. Br f Nutr 1986;55:13-22.

29 Barbee RA. Methodological issues in the assessment of atopy. In: Weiss ST, Sparrow D, eds. Airway responsiveness and atopy in the development of chronic lung disease. New York: Raven Press, 1989:121-55.

30 Burney PGJ, Britton JR, Chinn S, Tattersfield AE, Papacosta AO, Kelson MC, et al. Descriptive epidemiology of bronchial reactivity in an adult population: results from community study. Thorax 1987;42:38-44.

31 Higgins BG. Measurement of bronchial reactivity and peak expiratory flow variability in epidemiological studies of asthma. MD Thesis, University of Manchester, 1989.

32 Health Education Authority. The smoking epidemic. Counting the cost in England. Volume 3. Trent Regional Health Authority. London: Health Education Authority, 1991.

33 Fulton M, Thomson M, Elton RA, Brown S, Wood DA, Oliver MF. Cigarette smoking, social class and nutrien intake: relevance to coronary heart disease. Eur $\mathcal{f}$ Clin Nutr 1988;42:797-803.

34 Welty C, Weiss ST, Tager IB, Munoz A, Becker C, Speizer $\mathrm{FE}$, et al. The relationship of airways responsiveness to cold air, cigarette smoking, and atopy to respiratory symptoms and pulmonary function in adults. Am Rev Respir Dis 1984;130:198-203.

35 Bakke PS, Baste V, Gulsvik A. Bronchial responsiveness in a Norwegian community. Am Rev Respir Dis 1991;143:317-

36 Cerveri I, Bruschi C, Zoia MC, Maccarini L, Grassi M Lebowitz MD, et al. Smoking habit and bronchial reactivity in normal subjects. Am Rev Respir Dis 1989;140. $191-6$.

37 O'Connor GT, Sparrow D, Segal MR, Weiss ST. Smoking, atopy and methacholine airway responsiveness among 1989;140:1520-6.

38 Rijcken B, Schouten JP, Weiss ST, Speizer FE, Van Der Lende $R$. The relationship of nonspecific bronchial responsiveness to respiratory symptoms in a random population sample. Am Rev Respir Dis 1987;136:62-8.

39 Woolcock AJ, Peat JK, Salome CM, Yan K, Anderson SD, Schoeffel RE, et al. Prevalence of bronchial hyperresponsiveness and asthma in a rural adult population. Thorax 1987;421:361-8.

40 Ware JH, Dockery DW, Spiro A, Speizer FE, Ferris BG. Passive smoking, gas cooking, and respiratory health in hildren living in six cities. Am Rev Respir Dis 1984;129:366-74.

41 Lebowitz MD, Burrows B. Respiratory symptoms related to smoking habits of family adults. Chest 1976;69:48-50.

42 Holland WW, Kasap HS, Colley JRT, Cormack W. Respiratory symptoms and ventilatory function: a family study. $B r$ f Prev Soc Med 1969;23:77-84.

43 Krzyzanowski M, Robbins DR, Lebowitz MD. Smoking cessation and changes in respiratory symptoms in two
populations followed for 13 years. Int $\mathfrak{f}$ Epidemiol 1993;22:666-73. 